\title{
Genetic constraints on mating system evolution in the cleistogamous annual Impatiens pallida: inbreeding in chasmogamous flowers
}

\author{
STEVEN C. STEWART \\ Department of Botany, University of Guelph, Guelph, Ontario, Canada N1G 2W1
}

\begin{abstract}
Each Impatiens pallida individual has both a selfing mode of reproduction (cleistogamy) and a potentially outcrossing mode of reproduction (chasmogamy). The persistence of such a mating heteromorphism is in direct contrast to the theoretical expectation that mixed-mating strategies are evolutionarily unstable. Studies designed to detect fitness advantages of chasmogamous reproduction find only slight differences in the fitness of seed from the two reproductive modes. Inbreeding in chasmogamous flowers could cause these results. This hypothesis was tested by estimating the parameters of the correlated matings model for each of three generations in a natural population of I. pallida using multilocus electrophoretic data from 8934 chasmogamous seed sampled from 1080 individuals. Effective selfing in chasmogamous flowers averaged more than 0.50 , changing from 0.66 to 0.54 to 0.48 over three generations. Geitonogamous selfing comprised approximately 80 per cent of this inbreeding in each generation: the remainder was mating among relatives. The correlation of selfing and the correlation of outcrossed paternity within and among the chasmogamous flowers of individuals were moderate in each generation, ranged within +0.11 to +0.21 and changed little over three generations. Individuals that were further from their nearest neighbour or were shorter produced a greater proportion of inbred chasmogamous seed. Those that produced more chasmogamous flowers had higher rates of geitonogamous selfing. Taken together these results are strong evidence that substantial inbreeding occurred in chasmogamous flowers through both geitonogamous selfing and biparental inbreeding, that this inbreeding caused the genetic correlation of chasmogamous sibs to be more similar to the genetic correlation among completely selfed sibs than to the genetic correlation among completely outcrossed sibs, that effective selfing within chasmogamous flowers can change over generations and be influenced by plant architecture and pollinator behaviour, and that chasmogamous flowers of $I$. pallida have a stable, partially selfing mating strategy.
\end{abstract}

Keywords: cleistogamy, correlated matings, genetic covariance, Impatiens, inbreeding, sibs.

\section{Introduction}

Theory predicts that if a mating system includes both selfing and outcrossing, it may not be evolutionarily stable. Fisher (1941), for example, argues that selffertilization will increase until the population becomes completely selfing because any mutant allele that increases the rate of self-fertilization has an automatic transmission advantage. Processes, such as inbreeding depression, sib competition, pollen discounting, seed abortion and differential resource allocation, that might balance selfing's transmission advantage, require restrictive conditions for stability that may rarely occur in natural populations (Jain, 1976; Nagylaki, 1976; Solbrig, 1976; Lloyd, 1979, 1980; Wells, 1979; Stephenson, 1981; Charnov, 1982; Willson \& Burley, 1983; Feldman \& Christiansen, 1984; Holsinger et al., 1984; Schoen \& Lloyd, 1984; Lande \& Schemske, 1985; Campbell, 1986; Uyenoyama, 1986; Holsinger, 1992).

Cleistogamous species, in which each individual has both a selfing mode of reproduction (cleistogamy) and a potentially outcrossing mode of reproduction (chasmogamy), contradict theoretical expectations that 
mixed-mating strategies are unstable. These species have attracted considerable attention because their floral heteromorphism provides a model system for comparing the fitness consequences of self-fertilization in cleistogamous and chasmogamous flowers and cross-fertilization in chasmogamous flowers. Many studies, for example, have compared the relative fitness of seed produced by cleistogamous and chasmogamous flowers (c.g. Schemske, 1978; Waller, 1980; Mitchell-Olds \& Waller, 1985; Schmitt et al., 1985; Antlfinger, 1986) and have found only small, or no, fitness differences between cleistogamous and chasmogamous seed. These results, however, do not necessarily imply that self- and cross-fertilized seed have equal fitness because chasmogamous flowers may inbreed. If chasmogamous flowers inbreed, then fitness differences of cleistogamous and chasmogamous seed could be small, even when fitness differences between inbred and non inbred seed are not.

Chasmogamous flowers can produce inbred seed in several different ways (Lloyd \& Schoen, 1992). For example, pollen from a chasmogamous flower may fertilize its own ovules (within-flower selfing) or pollen from one chasmogamous flower may fertilize the ovules of another chasmogamous flower on the same individual (geitonogamous selfing). Chasmogamous flowers also will produce inbred seed when pollen and ovule parents are related (biparental inbreeding). Each of these types of inbreeding (and positive covariances between them) increases the genetic relatedness among sibs and, therefore, increases both the genetic covariance among sibs and the genetic variance among sibships. These genetic sib relationships are important because they may influence the selection pressures experienced by progeny produced in chasmogamous and cleistogamous capsules (Cockerham \& Weir, 1984) and may, therefore, be used to test theories of mating system evolution that involve inbreeding depression (Darwin, 1862, 1876, 1877; Wright, 1977; Charlesworth \& Charlesworth, 1987; Ziehe \& Roberds, 1989), differential resource allocation (Charlesworth \& Charlesworth, 1981; Charnov, 1982), reproductive assurance (Baker, 1955, 1959; Lloyd, 1979; Dole, 1992), the competitive interactions among sibs through sib competition (Schmitt \& Ehrhardt, 1987; McCall et al., 1989; Kelley, 1989) and selective fruit and flower abortion (Lloyd, 1980; Stephenson, 1981; Willson \& Burley, 1983).

Impatiens pallida and its close relative I. capensis have become important model systems for testing theories of plant mating system evolution. Each species is a cleistogamous annual, common in wet areas of the northern United States and southern Canada (Carroll, 1919). The pattern of resource allocation (Schemske,
1978; Waller, 1979) and relative titness of cleistogamous and chasmogamous reproduction (Waller, 1984; Mitchell-Olds \& Waller, 1985; Antlfinger, 1986; Schmitt \& Ehrhardt, 1987, 1990; McCall et al., 1989) have been studied. Inbreeding within chasmogamous flowers may be common in these species. Waller \& Knight (1989) reported selfing rates ranging from 0.29 to 0.71 in populations of $l$. capensis. Schoen \& Lloyd (1992) used a floral manipulation experiment to detect substantial geitonogamous selfing in a population of $I$. pallida. Biparental inbreeding also may be common in these species because pollen and seed dispersal are limited (Schmitt et al., 1985) and because neighbours may be related because of local adaptation (Stewart \& Schoen, 1987). The mating event correlations needed to find the quantitative genetic relationships among sibs and the fitness consequences of inbreeding in chasmogamous flowers are not known for either species.

In this paper the proportion of different mating events occurring in three generations of a natural population of $I$. pallida is estimated using multilocus genetic data and mating system estimation models. The genetic relationships among chasmogamous and cleistogamous sibs are determined and selfing rate variation among individuals is related to several plant characteristics associated with pollinator behaviour.

\section{Materials and methods}

An extensive population of $I$. pallida inhabiting a mixed deciduous forest near Webster's Falls, Dundas, Ontario, Canada was sampled in 1990, 1991 and 1992. In the first year, 13 permanent sampling transects were established by choosing a starting point and direction at random. Individuals were sampled along the transects as nearest neighbour pairs. In each year and for each transect, an individual and its nearest neighbour were sampled at the starting point of the transect, then the sampling location was moved at least $1 \mathrm{~m}$ along the transect, where another pair was sampled. This process was repeated for the length of the transect.

Seed from two chasmogamous seed capsules was taken from each sampled individual. Infrequently, seed from additional chasmogamous capsules was taken to increase the seed sample to at least six chasmogamous seed of each sampled individual. The 1990 sample included 2780 seeds sampled from 352 individuals (mean of 7.9 seeds per family). In 1991, 3132 seeds were sampled from 368 individuals (mean of 8.5 seeds per family). In 1992, 3022 seeds were sampled from 360 individuals (mean of 8.4 seeds per family). The height, number of lateral branches, number of chas- 
mogamous flowers, the proportion of chasmogamous versus cleistogamous reproduction and nearest neighbour distances of each sampled plant were recorded each year.

Sampled seed was stored on ice in the field, transported tc the laboratory, homogenized in the $\mathrm{pH} 7.3$ extraction buffer described by Marty et al. (1984), and then stored at $-70^{\circ} \mathrm{C}$. Five polymorphic enzyme loci were assayed in each of the 8934 seeds using starch gel electrophoresis run in a $\mathrm{pH} 8.0$ Tris-citrate buffer (Wendel \& Weeden, 1989): shikimic dehydrogenase ( $S k d$, E.C. 1.1.1.25), malic enzyme (Me. E.C. 1.1.1.40), isocitrate dehydrogenase (Idh, E.C. 1.1.1.41), glucophosphate transaminase ( $G p t$, E.C. 2.6.1.2) and fluorescent esterase (Fes, E.C. 3.1.1.1). Inheritance of these loci was confirmed using segregation patterns of seed from cleistogamous fruits.

The correlated matings model is a parametric approach to mating system estimation that accounts for covariances among mating events (Ritland, 1988, 1989; Brown, 1990). Chasmogamous flowers (which can inbreed) could, for example, produce sibs outcrossed to different pollen donors (half-sibs), sibs outcrossed to a single pollen donor (full-sibs), a mixture of both outcrossed half- and full-sibs, sibs completely selffertilized or a mixture of selfed and outcrossed sibs. This model estimates the frequencies of the four mating event combinations possible for pairs of sibs: selfed-selfed, selfed-outcrossed, both outcrossed to the same pollen parent (full-sibs), both outcrossed to different pollen parents (half-sibs). These mating event combinations are expressed in terms of the effective selfing rate, the inbreeding coefficient of parents, the covariance of effective selfing and inbreeding coefficient, and two mating event correlations: the correlation of selfing (this correlation is positive whenever both sibs are selfed more often than expected assuming independence) and the correlation of outcrossed pollen paternity (this correlation is positive whenever both sibs are outcrossed more often than expected assuming independence) (Schoen, 1985; Brown et al., 1987; Ritland, 1988, 1989; Brown, 1990).

The proportion of geitonogamous selfing in chasmogamous flowers was estimated as the multilocus selfing rate calculated from the same genotypic data using the multilocus mixed-matings model (Ritland, 1990). Although the effective selfing rate includes inbreeding contributed by mating among relatives and by self-fertilization, the selfing rate of the multilocus mixed-matings model only includes the contribution from self-fertilization (Ritland, 1984). Geitonogamous selfing is the only mode of self-fertilization possible in chasmogamous flowers of $I$. pallida because withinflower self-fertilization cannot occur (the androecium of an Impatiens chasmogamous flower physically covers the stigma until it falls off and the stigma is not receptive until the following day) (Wood, 1975; Schemske, 1978).

Ritland's estimation programs were used to find the maximum-likelihood estimates of the parameters of the correlated matings model and the multilocus mixedmatings models as minimum-variance averages over loci for each of 1000 bootstrap replicates (Ritland, 1990). Each bootstrap replicate was formed by resampling sib-pairs from the sampled progeny array for each maternal individual (Ritland, 1990). This was done separately for each generation. Parameter estimates were considered equal to the median of the resample estimate distribution and the upper and lower limits of the approximate 95 per cent confidence interval were considered equal to the 97.5 and 2.5 percentiles of the distribution (Efron, 1979). Parameter estimates were considered significantly different if and only if their 95 per cent confidence intervals did not overlap (Manly, 1991). This criterion was more conservative than standard parametric and nonparametric tests (S. C. Stewart, unpublished data). Measurements data were analysed using Pearson product-moment correlations.

Cockerham \& Weir (1984) showed how the covariances among mating events contribute to the genetic relatedness among progeny in partially selfing populations. They showed that the total genetic variance of a quantitative character can be partitioned into five quadratic components: additive genetic variance, dominance genetic variance and three dominance components that relate to a homozygous population (Jacquard, 1974; Cockerham \& Weir, 1984). Ritland (1989) extended their results by showing that the parameters of the correlated matings model determine the five quadratic components and the genetic covariance among sibs. The genetic covariance among sibs is a weighted sum of the five components. The weighting coefficient of each quadratic component was calculated for sibs within the same cleistogamous capsule and for sibs within the same chasmogamous capsule following Cockerham \& Weir (1984) and Ritland (1989).

\section{Results}

Allele frequencies of the five loci and $\chi^{2}$ goodness-offit tests appear in Table 1. Diallelic data provide eight degrees of freedom and the model estimates four parameters so that the $\chi^{2}$ tests have four degrees of freedom to test the goodness-of-fit (Ritland, 1989). There was a good fit between the model and the data for at least two loci in each generation (Table 1). 
Departures from model expectations in the other loci were often an excess of sib-pairs comprised of one homozygote and one heterozygote from a homozygous maternal parent. Sampling relatively few capsules from each parent and variation among the types of mating events occurring within each capsule may have caused this pattern of deviation (Ritland, 1989). Deviations were not large and, therefore, estimates based on data from all five loci are reported (Ritland, 1989).

The parental coefficient of inbreeding averaged 0.70 in 1990 , increased to 0.76 in the next generation
$(P<0.05$, Table 2$)$ and then changed little in the next generation, equalling $0.75(P>0.05$, Table 2$)$. Inbreeding at the population level includes inbreeding through past cleistogamous reproduction in addition to past geitonogamous selfing and biparental inbreeding in chasmogamous flowers.

The multilocus selfing rate of chasmogamous flowers (equivalent to geitonogamous selfing to chasmogamous flowers) averaged 0.51 in 1990 , decreased to 0.40 and then to 0.34 in the following generations $(P<0.05$, Table 2$)$. The effective selfing rate of chas-

Table 1 Allele frequency estimates at five allozyme loci and $\chi^{2}$ goodness-of-fit tests on an individual locus basis for a natural population of Impatiens pallida from Ontario, Canada

\begin{tabular}{|c|c|c|c|c|c|c|c|}
\hline \multirow[b]{2}{*}{ Locus } & \multirow[b]{2}{*}{ Allele } & \multicolumn{2}{|c|}{$1990(N=2780)$} & \multicolumn{2}{|c|}{$1991(N=3132)$} & \multicolumn{2}{|c|}{$1992(N=3022)$} \\
\hline & & Frequency & $\chi^{2}$ & Frequency & $\chi^{2}$ & Frequency & $\chi^{2}$ \\
\hline \multirow[t]{2}{*}{$I d h$} & 1 & 0.619 & \multirow[t]{2}{*}{6.58} & 0.641 & \multirow[t]{2}{*}{7.09} & 0.631 & \multirow[t]{2}{*}{8.29} \\
\hline & 2 & 0.381 & & 0.359 & & 0.369 & \\
\hline \multirow[t]{2}{*}{ Me } & 1 & 0.438 & \multirow[t]{2}{*}{8.06} & 0.459 & \multirow[t]{2}{*}{4.92} & 0.460 & \multirow[t]{2}{*}{$11.02^{*}$} \\
\hline & 2 & 0.562 & & 0.541 & & 0.540 & \\
\hline \multirow[t]{2}{*}{ Skd } & 1 & 0.240 & \multirow[t]{2}{*}{$11.98^{*}$} & 0.236 & \multirow{2}{*}{$31.01^{*}$} & 0.238 & \multirow[t]{2}{*}{9.46} \\
\hline & 2 & 0.760 & & 0.764 & & 0.762 & \\
\hline \multirow[t]{2}{*}{ Fes } & 1 & 0.228 & \multirow[t]{2}{*}{$46.69^{*}$} & 0.273 & \multirow{2}{*}{$16.68^{*}$} & 0.266 & \multirow{2}{*}{$13.88^{*}$} \\
\hline & 2 & 0.772 & & 0.727 & & 0.734 & \\
\hline \multirow[t]{2}{*}{$G p t$} & 1 & 0.797 & \multirow[t]{2}{*}{$69.39^{*}$} & 0.743 & \multirow[t]{2}{*}{5.22} & 0.768 & \multirow[t]{2}{*}{$19.22 *$} \\
\hline & 2 & 0.203 & & 0.257 & & 0.232 & \\
\hline
\end{tabular}

$N$ is the total number of progeny assayed in that generation.

$\chi^{2}$ values have four degrees of freedom (Ritland, 1989).

${ }^{*} P \leqslant 0.05$.

Table 2 Estimates of inbreeding coefficient of parents, effective selfing rate of chasmogamous flowers, covariance of effective selfing rate with parental inbreeding level, correlation of selfing, correlation of outcrossed paternity, and the multilocus selfing rate of chasmogamous flowers for three generations in a natural population of Impatiens pallida from Ontario, Canada

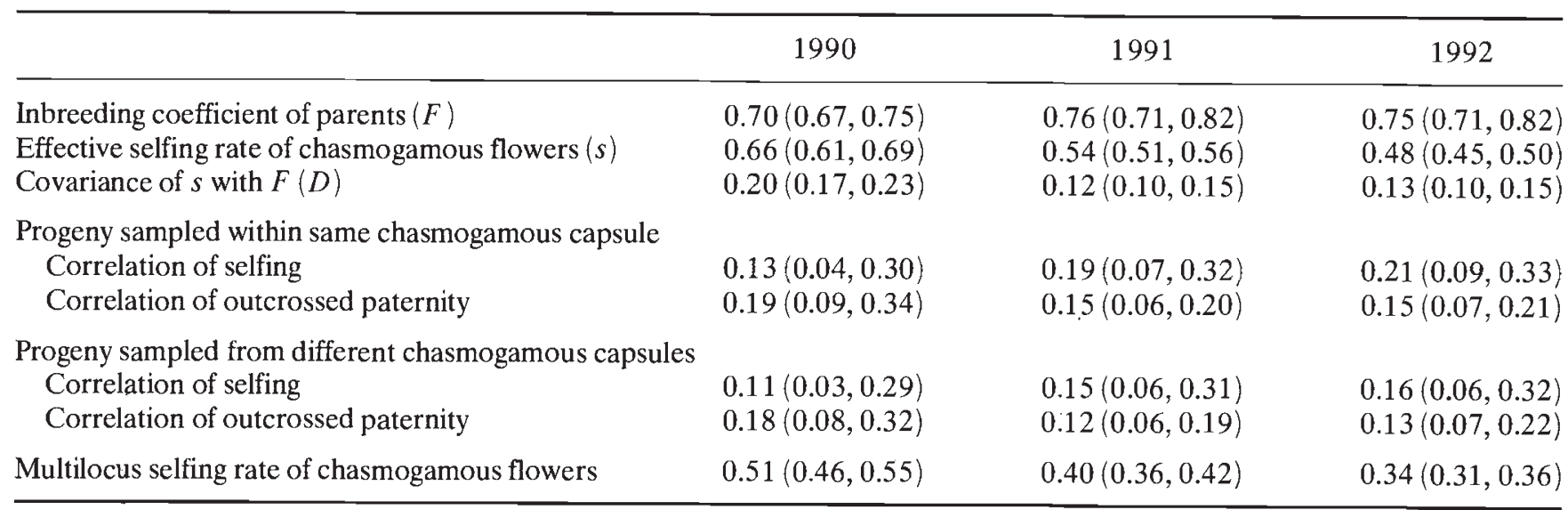

Estimates are median values from 1000 bootstrap replicates using maximum-likelihood minimum-variance over loci criteria. $95 \%$ confidence intervals based on bootstrap distribution follow median estimates in parentheses. 
mogamous flowers averaged 0.66 in 1990 , decreased to 0.54 and then to 0.48 in the following generations $(P<0.05$, Table 2$)$. Effective selfing rates include both current geitonogamous selfing and biparental inbreeding (Ritland \& Ganders, 1985).

Effective selfing rate and parental coefficient of inbreeding covaried closely in each generation (Table 2 ). This covariance ranged from 0.12 to 0.20 among generations, which was approximately 70 per cent of the maximum possible values.

When sib-pairs were sampled from the same chasmogamous capsule, the correlation of selfing and the correlation of outcrossed paternity were both moderate and positive in each generation (Table 2). The correlation of selfing averaged 0.18 , ranged within 0.13 to 0.21 and did not differ significantly among generations. The correlation of outcrossed paternity averaged 0.16 , ranged within 0.15 to 0.19 and did not differ significantly among generations.

When sib-pairs were sampled from different chasmogamous capsules, both the correlation of selfing and the correlation of outcrossed paternity were reduced, but only slightly (and non significantly) (Table 2). The correlation of selfing averaged 0.14 and did not differ significantly among generations. The correlation of outcrossed paternity also averaged 0.14 and did not differ significantly among generations.

The impact of these correlations can be considered by comparing the proportion of sib-pairs with those expected if the correlations were zero. Averaging across generations, 0.36 of the sib-pairs from the same chasmogamous capsule were both produced by selfing, 0.40 were comprised of one selfed seed and one outcrossed seed, 0.20 were half-sib pairs, and 0.04 were full-sib pairs. If the correlation of selfing were zero, only 0.26 of the sib-pairs from the same chasmoga- mous capsule would both be produced by selfing. If the correlation of outcrossed paternity were zero, none of the sib-pairs from the same chasmogamous capsule would be full-sibs and fewer of the sib-pairs would be half-sibs.

Effective selfing rate estimates of individual plants were positively correlated with the distance to their nearest neighbour in each generation $(r=+0.15$, $+0.11,+0.17 ; P<0.05 ; n=352,368,360)$ and negatively correlated with plant height $(r=-0.10$, $-0.11,-0.13 ; P<0.05 ; n=352,368,360)$, i.e. the proportion of inbred seed produced in an mdividual plant's chasmogamous flowers was greater when they were more distant from their nearest neighbours and when they were shorter. No relationship was found between the effective selfing rate of individual plants and other morphological characters.

Estimates of individual plant multilocus selfing rates were negatively correlated with plant height in each year $\langle r=-0.12,-0.10,-0.14 ; P<0.05 ; n=352$, $368,360)$ and positively correlated with the number of chasmogamous flowers in $1990(r=+0.10, P<0.05$, $n=352)$ and $1992(r=+0.12, P<0.05, n=368)$. The correlation in 1991 was similar but not significant $(r=+0.09, P<0.09, n=360)$, i.e. the proportion of seed produced by geitonogamous selfing among the chasmogamous flowers of an individual was greater when the individual was shorter and when it produced more chasmogamous flowers. No relationship was found between the multilocus selfing rate of individual plants and other morphological characters.

The coefficients of each quadratic component of the average genetic covariance among cleistogamous and chasmogamous seed for each generation appear in Table 3. Coefficients for seed from individual chasmogams were not calculated separately from those

Table 3 Estimates of coefficients of the quadratic components of genetic covariance between two sibs sampled from capsules produced by chasmogamous and cleistogamous flowers

\begin{tabular}{|c|c|c|c|c|c|c|}
\hline \multirow[b]{3}{*}{ Quadratic component of genetic covariance } & \multicolumn{6}{|c|}{ Generation } \\
\hline & \multicolumn{2}{|c|}{1990} & \multicolumn{2}{|c|}{1991} & \multicolumn{2}{|c|}{1992} \\
\hline & $\mathrm{CH}$ & $\mathrm{CL}$ & $\mathrm{CH}$ & CL & $\mathrm{CH}$ & CL \\
\hline Coefficient for additive genetic variance & 0.35 & 0.42 & 0.36 & 0.44 & 0.37 & 0.44 \\
\hline Coefficient for dominance genetic variance & 0.05 & 0.08 & 0.05 & 0.06 & 0.05 & 0.06 \\
\hline Coefficient for variance of dominance in a PMH & 0.34 & 0.74 & 0.27 & 0.79 & 0.22 & 0.78 \\
\hline Coefficient for covariance of dominance with additive effects in a PMH & 0.87 & 1.55 & 0.72 & 1.64 & 0.62 & 1.62 \\
\hline Coefficient for average squared dominance effects in a PMH & 0.02 & 0.05 & 0.02 & 0.05 & 0.01 & 0.05 \\
\hline
\end{tabular}

$\mathrm{CH}$, chasmogamous; $\mathrm{CL}$, cleistogamous; $\mathrm{PMH}$, population made homozygous.

Values calculated from correlated mating model parameters estimated for three generations of a natural population of Impatiens pallida from Ontario, Canada using equations described in Weir \& Cockerham (1984) and Ritland (1989). 
for seed from different chasmogams of a single individual because there is no evidence in these data that a difference exists (Table 2). Sibs from chasmogams share an average of 36 per cent of the additive genetic variance (which is nearly a 50 per cent increase over the 25 per cent shared by outbred half-sibs) and an average of 5 per cent of the dominance variance (outbred half-sibs share none of the dominance variance). In the Impatiens population, the three dominance components that relate to populations made homozygous were significantly greater than zero (the expected value for noninbreeding populations) and moderately large: each is approximately half the maximum value (maximum values are attained in sibs from cleistogams) (Table 3).

\section{Discussion}

\section{Inbreeding in chasmogamous flowers}

Chasmogamous flowers of I. pallida are not uniformly outcrossed. More than a third of the seed produced by chasmogamous flowers each generation were self-fertilized via geitonogamous selfing (multilocus selfing rates in Table 2). Mating among relatives increased the effective rate of self-fertilization above 0.50 (Table 2). These selfing rates are within the range of selfing rate estimates reported for $I$. capensis (selfing estimates range from 0.29 to 0.71 ) (Waller \& Knight, 1989). The I. pallida population was, however, more inbred than most of the I. capensis populations. This population of I. pallida may produce a larger proportion of its seed through cleistogamy than those of $I$. capensis but the differences in $F$ between the species may be due to chance alone. Sample variances for $F$ are expected to be large because the variance among loci is maximal for selfing rates within the entire seed crop near 85 per cent (Cockerham \& Weir, 1983), as in this population, and because the sampling error of $F$ is expected to be large (Ritland, 1989). The precision of the estimates of $F$ reported here is due to the large number of families used in the analysis, the fit of the data to the correlated matings model and, to a lesser extent, the number of loci and number of progeny included.

Correlations between geitonogamous selfing and the number of chasmogamous flowers, between individual effective selfing rates and nearest neighbour distance, and between both selfing rates and plant height suggest that selfing rates have a large environmental component because the number of chasmogamous flowers, nearest neighbour distance and plant height are largely determined by environmental conditions (Schemske, 1978; Mitchell-Olds \& Waller, 1985). These correlations also suggest that pollinators move pollen from one flower to another on the same individual more often as interplant distances increase, that pollinators may visit the compact inflorescences of shorter individuals more intensively, that pollinators move pollen from one chasmogamous flower to another on the same individual more often when there are more chasmogamous flowers on an individual and that changes in chasmogamous selfing over generations may have been caused by changes in pollinator activity (S. C. Stewart, unpublished data). Although the correlations were not large, their persistence over generations may indicate their relevance to chasmogamous flower pollination. In addition, the correlations probably underestimate the true correlations because the estimates of the selfing rates of individuals had somewhat large sampling errors (S. C. Stewart, unpublished data).

The correlation between rate of geitonogamous selfing and the number of chasmogamous flowers produced suggests that the fitness gain curve of resource allocation to chasmogamous reproduction may be saturating (Charnov, 1982). Further resource allocation to chasmogamous reproduction may create ever diminishing fitness gains because cross-fertilization becomes less likely. This could constrain selection for greater chasmogamous reproduction, while inbreeding depression constrains selection for greater cleistogamous reproduction, leading to a stable, partial selfing, mixed-mating system in chasmogamous flowers.

\section{Correlation of selfing}

While both geitonogamous selfing and biparental inbreeding contribute to the correlation of selfing, the correlation of selfing does not include the contribution to the total correlation of selfing made by population subdivision. The contribution from population substructure equals $D^{2} /(s(1-s) F(1-F))$, where $D$ is the covariance of effective selfing with parental inbreeding level, $s$ is the effective selfing rate and $F$ is the parental inbreeding level (Ritland \& Ganders, 1985). In cleistogamous species, both past cleistogamous reproduction and past inbreeding in chasmogamous flowers will contribute to this substructure correlation. Population substructure induces a correlation between effective selfing and parental inbreeding because matings among neighbours in neighbourhoods with a history of more inbreeding produce progeny that are themselves more inbred than matings among neighbours in neighbourhoods with a history of less inbreeding. Cleistogamous reproduction contributes to inbreeding within neighbourhoods, and chasmogamous matings among neighbours in neighbourhoods with a greater proportion of cleistogamous reproduction will produce 
progeny that are more inbred than chasmogamous matings among neighbours in neighbourhoods with a lower proportion of cleistogamous reproduction. The covariance of effective selfing in chasmogamous flowers with parental inbreeding may, therefore, increase whenever past cleistogamous reproduction and past inbreeding in chasmogamous flowers increase the relatedness of neighbours and, thus, the relatedness of parents involved in biparental inbreeding. The 'substructure correlation' equalled 0.85 in 1990 and decreased to 0.32 in 1991 (nonoverlapping 95 per cent confidence intervals) and remained at a similar value, 0.36 , in 1992. This generational change probably reflects an additional contribution to the substructure correlation through greater cleistogamous reproduction in some neighbourhoods in the generations before 1990 or, equivalently, a reduced contribution to the substructure correlation through less cleistogamous reproduction in some neighbourhoods in the 1991 and 1992 generations.

Adding the correlation of selfing within the same chasmogamous capsule to these 'substructure correlations' provides the total correlations of selfing: 0.98 in $1990,0.51$ in 1991 and 0.57 in 1992. Population substructure contributed three to four times more to the total correlation than to the correlation of selfing. Such large total correlations of selfing mean that most of the seeds in many chasmogamous capsules are selfed. This implies that the genetic relationships among seed from the chasmogams and cleistogams of each individual are similar and can, therefore, at least partially explain the lack of detectable fitness differences among seed from cleistogamous and chasmogamous flowers (Schemske, 1978; Waller, 1980; Mitchell-Olds \& Waller, 1985; Schmitt et al., 1985; Antlfinger, 1986).

\section{Correlation of outcrossed paternity}

In each generation, the correlation of outcrossed paternity (and the correlation of selfing) remained moderate and positive, though slightly smaller, when pairs were sampled from different chasmogams capsules of the same maternal individual relative to pairs sampled from the same chasmogamous capsule (Table 2). Sibs within chasmogams were, therefore, not more closely related to each other than sibs from different chasmogams of the same maternal individual. This pattern indicates that the genetic composition of fertilizing pollen was not strongly differentiated among chasmogams and is consistent with repeated matings among a small set of neighbouring individuals and limited pollen carry-over. Ritland (1989) shows that random outcrossing to five neighbours could induce a correlation of outcrossed paternity of 0.20 .
Waller \& Knight (1989) estimated a conceptually similar correlation in populations of $I$. capensis and reported values ranging from -0.92 to +0.44 . Comparisons are problematic because their 'genotypic correlation between truly outcrossed mates' is not equivalent to Ritland's correlation of outcrossed paternity. In addition, the sample variance of the 'genotypic correlation between truly outcrossed mates' is not known and the sample variances of the I. pallida correlation estimates are large, even though each is based on nearly 15000 genotype determinations (Table 2).

Interestingly, the mating event correlations in the Mimulus guttatus populations studied by Ritland (1989) are similar to those of I. pallida, except that the within-capsule correlations of selfing of $M$. guttatus are nearly twice as large as those for I. pallida. This difference is probably because of the difference in the fate of the androecium in each species. In M. guttatus, withinflower self-fertilizing can occur when a flower's stamens drag across the stigma during corolla abscission (Ritland, 1989; Dole, 1992). In I. pallida, withinflower self-fertilization does not occur because the androecium drops off before the stigma is receptive (Wood, 1975; Schemske, 1978).

\section{Evolutionary consequences of correlated matings in the chasmogamous flowers of I. pallida}

An important conclusion of this research is that the genetic relationships among seed from chasmogams and cleistogams are more similar than previously assumed. For example, the coefficients of each quadratic component of the average genetic covariance among cleistogamous and chasmogamous seed show that the genetic correlation of chasmogamous sibs is more similar to the genetic correlation among completely selfed sibs than to the genetic correlation among completely outcrossed sibs. The relative magnitudes of the coefficients of cleistogamous and chasmogamous sibs also reinforce the notion that dominance effects, such as inbreeding depression, will strongly influence the covariance among sibs and the variance among families in inbreeding populations with correlated matings. This may be especially important for seedling characters of Impatiens because MitchellOlds \& Bergelson (1990) found that early life cycle characters showed evidence of either dominance or maternal effects in $I$. capensis. However, the relative importance of the five quadratic components cannot be determined from the calculated coefficients alone (the variance components themselves must also be known) because each component contributes as the product of the component and its coefficient (Cockerham \& Weir, 1984). 
Another important aspect of these results is that the mating system of chasmogamous flowers of I. pallida was stable over three generations in this natural population. Rates of both geitonogamous and effective selfing in chasmogamous flowers ranged within a narrow interval over the three generations. The other mating system parameters and the correlations among selfing rates and plant characteristics were also stable over generations. This suggests that chasmogamous flowers of $I$. pallida have a stable, mixed-mating strategy.

The analysis of correlated matings also helps to establish the extent of gene flow within this population and its population structure. Populations of $I$. pallida tend to be highly inbred because of cleistogamous seed production (Waller, 1980; Cid-Benevento \& Schaal, 1986) and substantial inbreeding via geitonogamous selfing and biparental inbreeding in chasmogamous flowers (Waller \& Knight, 1989; Schoen \& Lloyd, 1992; and Table 2). Genetic neighbourhoods are small because of limited seed and pollen dispersal (Schmitt et al., 1985) and allelic variability is spatially autocorrelated in natural populations (Schoen \& Latta, 1989). These processes tend to produce and maintain an inbred population structure of small neighbourhoods comprised of genetically related individuals (Ritland, 1985, 1988) and induce a high substructure correlation (see above). Heterogeneous selection among neighbourhoods has also been reported in natural populations of I. pallida (Stewart \& Schoen, 1987). This balance of processes structures the population into a mosaic of genetically differentiated neighbourhoods that may sequester genetic variants within and maintain genetic variation among neighbourhoods. Within the neighbourhoods, competition among seedlings may occur among highly related neighbouring individuals. Seed produced by the two flower types will differ in their sib genetic covariances but the differences are limited by the correlated mating events and high effective selfing rates within chasmogamous flowers (Table 3). Such similar genetic covariances among chasmogamous and cleistogamous sibs constrain the fitness differences of chasmogamous and cleistogamous reproduction, change the selection experienced by progeny and may have influenced the mating system evolution of this species. Work is currently underway to test directly the response to selection on mating system characters by estimating realized heritabilities from the observed response to artificial selection applied to individuals in this population of I. pallida.

\section{Acknowledgements}

I thank Yvette Feig, Tom Chapman, Paul Kron, Allison Back and Phil Davis for field and laboratory assistance and Paul Kron, Brian C. Husband, Johanna Schmitt and Kermit Ritland for comments. This research was supported by the Natural Sciences and Engineering Research Council of Canada and the University of Guelph.

\section{References}

ANTLFINGER, A. E. 1986. Field germination and seedling growth of $\mathrm{CH}$ and $\mathrm{CL}$ progeny of Impatiens capensis (Balsaminaceae). Am. J. Bot., 73, 1267-1273.

BAKER, H. G. 1955. Self-compatibility and establishment after 'long distance' dispersal. Evolution, 9, 720-734.

BAKER, H. G. 1959. Reproductive methods as factors in speciation in flowering plants. Cold Spring Harbor Symp. Quant. Biol., 24, 177-191.

BROWN, A. H. D. 1990. Genetic characterization of plant mating systems. In: Brown, A. H. D., Clegg, M. T., Kahler, A. and Weir, B. S. (eds) Plant Population Genetics, Breeding and Genetic Resources, pp. 145-162. Sinauer Associates, Sunderland, MA.

BROWN, A. H. D., GRANT, J. E. AND PULLEN, R. 1987. Outcrossing and paternity in Glycine argyrea by paired fruit analysis. Biol. J. Linn. Soc., 29, 283-294.

CAMPBELL, R. 1986. The interdependence of mating structure and inbreeding depression. Theor. Pop. Biol., 30, $232-244$

CARroll, F, B. 1919. The development of the chasmogamous and cleistogamous flowers of Impatiens fulva. Contrib. Univ. Penn. Bot. Lab., 4, 144-183.

CHARLESWORTH, D. AND CHARLESWORTH, B. 1981. Allocation of resources to male and female functions in hermaphrodites. Biol. J. Linn. Soc., 15, 57-74.

CHARLESWORTH, D. AND CHARLESWORTH, B. 1987. Inbreeding depression and its evolutionary consequences. Ann. Rev. Ecol. Syst., 18, 237-268.

Charnov, E. 1982. The Theory of Sex Allocation. Princeton University Press, Princeton, NJ.

CID-BENEVENTO, C. R. AND SCHAAL, B. A. 1986. Variation in population growth rate in the woodland annual Impatiens pallida (Balsaminaceae). Am. J. Bot., 73, 1031-1042.

COCKERHAM, C. C. AND WEIR, B. S. 1983. Variance of actual inbreeding. Theor. Pop. Biol., 23, 85-109.

COCKERHAM, C. C. AND WEIR, B. S. 1984. Covariances of relatives stemming from a population undergoing mixed self and random mating. Biometrics, 40, 157-164.

DARWIN, C. R. 1862. The Various Contrivances by which Orchids are Fertilized by Insects. John Murray, London.

DARWIN, C. R. 1876. The Effects of Cross and Self-fertilization in the Vegetable Kingdom. John Murray, London.

DARWIN, C. R. 1877. The Different Forms of Flowers on Plants of the Same Species. John Murray, London.

DOLE, J. A. 1992. Reproductive assurance mechanisms in three taxa of the Mimulus guttatus complex (Scrophulariaceae). Am. J. Bot., 79, 650-659.

EFRON, B. 1979. Bootstrap methods: another look at the jackknife. Ann. Statist., 7, 1-26. 
FEldman, M. W. AND Christiansen, F. B. 1984. Population genetic theory of the cost of inbreeding. Am. Nat., 123, 642-653.

FISHER, R. A. 1941. Average excess and average effect of a gene substitution. Ann. Eugen., 11, 53-63.

HOLSINGER, K. E. 1992. Ecological models of plant mating systems and the evolutionary stability of mixed mating systems. In: Wyatt, R. W. (ed.) Ecology and Evolution of Plant Reproduction, pp. 169-191. Chapman \& Hall, New York.

HOLSINGER, K. E., FELDMAN, M. W. AND CHRISTIANSEN, F. B. 1984. The evolution of self-fertilization in plants: a population genetics model. Am. Nat., 124, 446-453.

JACQUARD, A. 1974. The Genetic Structure of Populations. Springer, New York.

JAIN, S. K. 1976. Evolution of inbreeding plants. Ann. Rev. Ecol. Syst., 7, 469-495.

KELLEY, S. E. 1989. Experimental studies of the evolutionary significance of sexual reproduction. VI. A greenhouse test of the sib-competition hypotheses. Evolution, 43, 1066-1074.

LANDE, R. AND SCHEMSKE, D. w. 1985. The evolution of selffertilization and inbreeding depression in plants. I. Genetic models. Evolution, 39, 24-40.

LLOYD, D. G. 1979. Some reproductive factors affecting the selection of self-fertilization in plants. Am. Nat., 113, 67-79.

LLOYD, D. G. 1980. Sexual strategies in plants. I. An hypothesis of serial adjustment of maternal investment during one reproductive season. New Phytol., 86, 69-79.

LLOYD, D. G. AND SCHOEN, D. J. 1992. Self- and cross-fertilization in plants. I. Functional dimensions. Int. J. Plant. Sci., 153, 358-369.

MCCALL, C., MITCHELL-OLDS, T. AND WALLER, D. M. 1989. Fitness consequences of outcrossing in Impatiens capensis: test of the frequency-dependent and sib-competition models. Evolution, 43, 1075-1084.

MANLY, B. F. J. 1991. Randomization and Monte Carlo Methods in Biology. Chapman \& Hall, London.

MARTY, T. L., O'MALLEY, D. M. AND GURIES, R. P. 1984. A Manual for Starch Gel Electrophoresis: New Microwave Edition. Staff paper series number 20. University of Wisconsin, Madison.

MITCHELL-OLDS, T. AND BERGELSON, J. 1990. Statistical genetics of an annual plant, Impatiens capensis. I. Genetic basis of quantitative variation. Genetics, 124, 407-415.

MITCHELL-OLDS, T. AND WALLER, D. M. 1985. Relative performance of selfed and outcrossed progeny in Impatiens capensis. Evolution, 39, 533-544.

NAGYLAKI, T. 1976. A model for the evolution of self-fertilization and vegetative reproduction. J. Theor. Biol., 58, 55-58.

RITLAND, K. 1984. The effective proportion of self-fertilization with consanguineous matings in inbred populations. Genetics, 106, 139-152.

RITLAND, K. 1985. The genetic structure of subdivided populations. I. Open mating model. Theor. Pop. Biol., 27, 51-74.

RITLAND, K. 1988. The genetic structure of subdivided populations. II. Correlated mating models. Theor. Pop. Biol., 34, 320-346.

RITLAND, K. 1989. Correlated mating in the partial selfer Mimulus guttatus. Evolution, 43, 848-859.

RITLAND, K. 1990. A series of FORTRAN computer programs for estimating plant mating systems. J. Hered., 81, 235-237.

RITLAND, K. AND GANDERS, F. R. 1985. Variation in the mating system of Bidens menziesii (Asteraceae) in relation to population structure. Heredity, 55, 235-244.

SCHEMSKE, D. W. 1978. Evolution of reproductive characteristics in Impatiens (Balsaminaceae): the significance of cleistogamy and chasmogamy. Ecology, 59, 596-613.

SCHMITT, J. AND EHRHARDT, D. 1987. A test of the sib-competition hypothesis for outcrossing advantage in Impatiens capensis. Evolution, 41, 579-590.

SCHMITT, J. AND EHRHARDT, D. 1990. Enhancement of inbreeding depression by dominance and suppression in Impatiens capensis. Evolution, 44, 269-278.

SCHMITT, J., EHRHARDT, D. AND SWARTZ, D. 1985. Differential dispersal of self-fertilized and outcrossed progeny in jewelweed (Impatiens capensis). Am. Nat., 126, 570-575.

SCHOEN, D. J. 1985. Correlation between classes of mating events in two experimental plant populations. Heredity, 55, 381-385.

SCHOEN, D. J. AND LATTA, R. 1989. Spatial autocorrelation of genotypes in populations of Impatiens pallida and Impateins capensis. Heredity, 63, 181-189.

SCHOEN, D. J. AND LLOYD, D. G. 1984. The selection of cleistogamy and heteromorphic diaspores. Biol. J. Linn. Soc., 23, 303-322.

SCHOEN, D. J. AND LLOYD, D. G. 1992. Self- and cross-fertilization in plants. III. Methods for studying modes and functional aspects of self-fertilization. Int. J. Plant Sci., 153, 381-393.

SOLBRIG, о. T. 1976. On the relative advantages of cross- and self-fertilization. Ann. Mo. Bot. Gard., 63, 262-276.

STEPHENSON, A. G. 1981. Flower and fruit abortion: proximate causes and ultimate functions. Ann. Rev. Ecol. Syst., 12, 253-279.

STEWART, s. C. AND SCHOEN, D. J. 1987. Pattern of phenotypic viability and fecundity selection in a natural population of Impatiens pallida. Evolution, 41, 1290-1301.

UYENOYAMA, M. K. 1986. Inbreeding and the cost of meiosis: the evolution of selfing in populations practising biparental inbreeding. Evolution, 40, 388-404.

WALLER, D. M. 1979. The relative costs of self- and cross-fertilized seeds in Impatiens capensis (Balsaminaceae). Am. J. Bot., 66, 313-320.

WALLER, D. M. 1980. Environmental determinants of outcrossing in Impatiens capensis. Evolution, 34, 747-761.

WALLER, D. M. 1984. Differences in fitness between seedlings derived from cleistogamous and chasmogamous flowers in Impatiens capensis (Balsaminaceae). Evolution, 38, 427-440.

WALLER, D. M. AND KNIGHT, S. E. 1989. Genetic consequences of outcrossing in the cleistogamous annual, Impatiens capensis. II. Outcrossing rate and genotypic correlations. Evolution, 43, 860-869. 
WELLS, H. 1979. Self-fertilization: advantageous or deleterious? Evolution, 33, 252-256.

WENDEL, J. F. AND WEEDEN, N. F. 1989. Visualization and interpretation of plant isozymes. In: Soltis, D. E. and Soltis, P. S. (eds) Isozymes in Plant Biology, pp. 5-45. Discorides Press, Portland, OR.

Willson, M. F. AND Burley, N. 1983. Mate Choice in Plants. Princeton University Press, Princeton, NJ. wood, C. E. 1975. The Balsaminaceae in the Southeastern United States. J. Arnold Arbor., 56, 413-426.

WRIGHT, s. 1977. Evolution and the Genetics of Populations, vol. 3, Experimental Results and Evolutionary Deductions. University of Chicago Press, Chicago, IL.

ZIEHE, M. AND ROBERDS, J. H. 1989. Inbreeding depression due to overdominance in partially self-fertilizing plant populations. Genetics, 121, 861-868. 